\title{
HOMONACIONALISMO COMO MOSAICO: VIAGENS VIRAIS, SEXUALIDADES AFETIVAS ${ }^{1}$
}

\author{
Jasbir K. Puar
}

\begin{abstract}
RESUMo
Neste artigo irei contextualizar o aumento do número de movimentos de gays e lésbicas no âmbito dos debates sobre os discursos dos direitos e da temática dos direitos, que é seguramente o mais forte afrodisíaco do liberalismo. Analiso o modo como a sexualidade se tornou parte de uma formação essencial na articulação de cidadãos plenos através dos vários registos, como género, classe e etnia, quer nacional, quer transnacionalmente. Este estudo posiciona claramente o homonacionalismo como categoria analítica necessária à compreensão e conceção histórica dos motivos pelos quais o estado de uma nação como simpatizante gay se tornou desejável à partida. Como a Modernidade, o homonacionalismo pode ser objeto de resistência e de resignificação, mas não pode ser excluído: todos somos condicionados por ele e através dele. $\mathrm{O}$ artigo encontra-se estruturado em três secções. Começo por apresentar uma panorâmica do projeto Terrorist Assemblages, prestando atenção, em particular, à utilização do termo "homonacionalismo". Em segundo lugar, discuto o homonacionalismo no contexto da Palestina/Israel, com o objetivo de demonstrar a relevância dos discursos sobre direitos sexuais e da narrativa de "lavagem cor-de-rosa" para a ocupação. Termino com uma reflexão acerca do potencial inerente ao pensamento da sexualidade, não como uma identidade, mas como mosaicos de sensações, afetos e forças. Esta viralidade da sexualidade destabiliza produtivamente as noções humanistas dos sujeitos da sexualidade, assim como a organização política que procura resistir aos discursos jurídicos instituídos com o objetivo de nomear e controlar estes sujeitos de sexualidade.
\end{abstract}

\section{Palavras-chave}

Homonacionalismo; mosaico; viralidade; sexualidades afetivas

\section{INTRODUÇÃO}

Este artigo tem como objetivo contextualizar o aumento do número de movimentos de gays e lésbicas no âmbito dos debates sobre os discursos dos direitos e da temática dos direitos, que é seguramente o mais forte afrodisíaco do liberalismo. ${ }^{2}$ As metas e os êxitos das organizações políticas de gays e lésbicas passaram a ser cada vez mais definidas e medidas através do prisma da legalização, conduzindo a um romance palpável com a descriminalização da sodomia em diversos contextos nacionais. Embora o discurso da lei possa servir, e serve muito bem, para reparar injustiças sociais, e os

\footnotetext{
' Este artigo foi originalmente apresentado em sessão plenária no congresso "Human Rights Beyond the Law: Politics Practices, Performances of Protest", organizado pela Jindal Global Law School, Índia, em setembro de 2011. Foi, posteriormente, publicado em inglês no número especial duplo da revista científica Jindal Global Law Review (Vol 4., Número 2, Parte II, de novembro de 2013), subordinado ao tema "Law, Culture and Queer Politics in Neoliberal Times", organizado por Oishik Sircar e Dipika Jain. O artigo também será publicado em Oishik Sircar e Dipika Jain (Eds.). New intimacies/ old desires: law, culture and queer politics in neoliberal times. Nova Delhi: Zubaan, no prelo.
}

${ }^{2} \mathrm{~A}$ caracterização dos direitos humanos como o mais forte afrodisíaco foi retirada do convite à apresentação de trabalhos para o workshop "Human Rights Beyond the Law", disponível em http://www.h- net.org/announce/show.cgi?ID=182227. 
sujeitos do discurso jurídico sejam esclarecidos e capazes de negociar sistemas jurídicos, mesmo quando sujeitos às suas forças disciplinares, o meu interesse neste caso tem como objetivo destabilizar a mensuração da mudança social e do "progresso" em termos de legalização. "A lei" encontra-se limitada naquilo que pode transmitir e criar; os limites com os quais nos deveremos preocupar não são os instrumentos legais per se, mas antes a dependência da lei da linguagem performativa que produz aquilo que simplesmente se propõe regular, incluindo a atribuição de um sujeito dessa lei. ${ }^{3}$ Embora estas limitações possam não implicar o abandono das intervenções legais sustentadas nos direitos, realçam a necessidade de responder às consequências não progressivas da legislação progressiva, bem como aos modos de porte corporal que desafiam os parâmetros identitários.

Começo por apresentar uma panorâmica do projeto Terrorist Assemblages, prestando atenção à utilização do termo "homonacionalismo", em particular. Em segundo lugar, discuto o homonacionalismo no contexto da Palestina/Israel, com o objetivo de demonstrar a relevância dos discursos sobre direitos sexuais e da narrativa de "lavagem cor-de-rosa" para a ocupação. Termino com uma reflexão acerca do potencial inerente ao pensamento da sexualidade, não como uma identidade, mas como mosaicos de sensações, afetos e forças. Esta viralidade da sexualidade destabiliza produtivamente as noções humanistas dos sujeitos da sexualidade, assim como a organização política que procura resistir aos discursos jurídicos instituídos com o objetivo de nomear e controlar estes sujeitos de sexualidade.

\section{HomonaCiONALISMO E OS SEUS DESCONTENTAMENTOS}

Na minha monografia Terrorist Assemblages: Homonationalism in Queer Times ${ }^{4}$ (doravante referida como TA), de 2007 , desenvolvo o enquadramento concetual de "homonacionalismo", que utilizo para descrever a utilização de "aceitação" e "tolerância" relativamente a sujeitos gays e lésbicas como barómetro de avaliação da legitimidade e capacidade para a soberania nacional. Desde os anos 90 que tenho vindo a preocupar-me cada vez mais com o coro presente no discurso feminista transnacional, bem como nas teorias queer, a bradar que a nação é heteronormativa e que o queer é inerentemente um marginal do estado-nação.

Embora o projeto tenha surgido na era política pós-11 de setembro dos Estados Unidos da América, a minha intenção em TA não era apenas demonstrar uma relação entre a instrumentalização dos corpos queer pelo Estado americano, nem a adoção dos interesses nacionalistas e, muitas vezes, xenófobos e imperialistas dos Estados Unidos pelas comunidades queer. Antes, assente no importante trabalho de Lisa Duggan sobre "homonormatividade" - a sua teorização do entroncamento da privatização das economias

\footnotetext{
3 Os discursos de direitos humanos reiteram um "antropocentrismo biopolítico" que exige uma reprodução do excecionalismo humano; Livingston, J. \& Puar, J. (2011). Introduction: interspecies, Social Text 29 (1 106), 3-14.

${ }^{4}$ Jasbir K. Puar (2005). Terrorist assemblages: homonationalism in queer times.
} 
neoliberais e o crescimento da aceitação interna das comunidades queer ${ }^{5}$ - o homonacionalismo é fundamentalmente uma crítica à forma como os discursos dos direitos liberais de lésbicas e gays produzem narrativas de progresso e modernidade que continuam a conceder a algumas populações o acesso a formas culturais e legais de cidadania, em detrimento do abandono parcial e integral dos direitos das restantes populações.

Posto de uma forma simples, o homonacionalismo corresponde à ascensão em simultâneo do reconhecimento legal, de consumidor e representativo dos sujeitos LGB$T Q$, e à restrição das prestações sociais, dos direitos dos imigrantes e da expansão do poder do Estado nas tarefas de supervisão, detenção e deportação. A narrativa do progresso dos direitos gays assenta, assim, no apoio do outro racial e sexualizado, para quem esse progresso foi outrora alcançado, mas que se encontra agora a regredir ou que ainda está para advir. Este processo baseia-se na sustentação da respeitabilidade dos sujeitos homossexuais relativamente à reiteração performativa da (homo e heteros)sexualidade perversa de natureza patológica dos outros raciais, especificamente dos outros Muçulmanos, sobre quem recaem as projeções orientalistas e neo-orientalistas. Por conseguinte, o Homonacionalismo não constitui simplesmente um sinónimo de racismo gay ou de outra forma de crítica da "conservadorização" das identidades gays e lésbicas, mas antes uma forma analítica de apreender os resultados de sucesso dos movimentos dos direitos liberais LGBT.

Neste ponto, deverei acrescentar - aspeto que irei desenvolver mais adiante - que não penso o homonacionalismo como uma identidade ou como um posicionamento; não se trata de mais um marcador destinado a separar um queer "bom" (progressista/ transgressivo/politicamente de esquerda) de um queer "mau" (esgotado/conservador/ politicamente falido). Pelo contrário, a minha teorização do homonacionalismo assenta num mosaico de forças, afetos, energias e movimentos de desterritorialização e de reterritorialização. Os mosaicos não se constituem num tempo linear, nem no âmbito de histórias, campos ou discursos discretos. Ao dar nome a um movimento nas políticas queer contemporâneas dos Estados Unidos, o homonacionalismo é útil apenas na medida como proporciona um modo de registar mudanças históricas no termo da Modernidade, mesmo que se tenha mobilizado nas próprias mudanças para cuja nomeação foi produzido. Podemos discutir os prós e os contras da instrumentalização da identidade sexual pelos enquadramentos de direitos humanos, mas não podemos omitir aquilo que eu defendo ser o cerne do problema: a insistência na própria noção de identidade ou a sua utilização por defeito. Através de um mosaico Deleuziano — originalmente designado, em francês, agencement, que significa, genericamente, padronização de arranjos - o homonacionalismo é rearticulado como um campo de poder, e não como uma atividade ou propriedade de qualquer Estado-nação, organização ou indivíduo. ${ }^{6}$

O homonacionalismo também é um processo, e não um evento ou um atributo. Designa uma mudança histórica na produção de Estados-nação a partir da insistência

\footnotetext{
5 Duggan, L. (2002). The twilight of equality: neoliberalism, cultural politics, and the attack on democracy.

${ }^{6}$ Para uma explicação mais detalhada da teoria do mosaico, ver Puar, J. (2012). I'd rather be a cyborg than a goddess. PhiloSOPHIA, 2 (1), 49-66.
} 
na heteronormatividade como forma de aumentar a inclusão da homonormatividade. Este processo não é coerente com o 11 de setembro enquanto momento temporal solitário; "isto" não começou com o 11 de setembro. Possuo algumas preocupações sobre o modo como o 11 de setembro parece funcionar como gatilho propulsor, incentivando uma perigosa reificação histórica (o que, por vezes, cinicamente se designa nos Estados Unidos como "indústria do 11 de setembro"). ${ }^{7}$ Olhando retrospetivamente, a partir do 11 de setembro, o meu interesse centrava-se no período de 40 anos da era pós-direitos civis que, através da política de inclusão liberal, continua a produzir o outro sexual como branco e o outro racial como heterossexual. E, muito embora as formas de viral Islamofobia explícita e a sensação crescente de fracasso do momento "pós-racial" do Presidente Obama tenham permitido expressões racistas mais explícitas, estas modalidades conservadoras podem ser diretamente questionadas melhor do que nunca. Mais do que nunca, estou convencida de que a crítica central do homonacionalismo reside em atacar os conluios insidiosos entre o racismo e o liberalismo. Esta convergência do racismo e da instrumentalização liberal progressiva das identidades sexuais outrora consideradas marginais conduziu a posições liberais pautadas pelo senso comum, como aquelas que se seguem: é claro que somos contra a guerra contra o terrorismo, mas e a homofobia dos muçulmanos? é claro que somos contra a ocupação do Médio Oriente pelos Estados Unidos, mas os iranianos continuam a enforcar homens homossexuais inocentes; é claro que apoiamos a revolução no Egito e a Primavera Árabe, mas os abusos sexuais das mulheres mostra que os egípcios são umas bestas. Estes tipos de reprodução binária entre os secularistas liberais iluminados e esses Outros, esses fanáticos religiosos racializados, são, não só intelectualmente redutores e politicamente ingénuos, como também simplesmente inaceitáveis. ${ }^{8}$

Defendo, porém, que nunca houve um aumento da sua permissão nos círculos de gays, lésbicas, feministas e de esquerda nos Estados Unidos e na Europa. ${ }^{9} \mathrm{O}$ único posicionamento liberal que perdura, e ao qual voltarei na minha discussão sobre a lavagem cor-de-rosa, é: é claro que apoiamos os Palestinianos na sua luta pela autodeterminação,

\footnotetext{
7 É interessante observar, aqui, as diferentes periodizações da Islamofobia. Naturalmente, poderemos apontar para o aumento das formas de Islamofobia global que coincidiram com a era de descolonização, a Revolução Iraniana de 1978-79 e o fim da Guerra Fria. A minha própria investigação (Terrorist Assemblages, capítulo um) acerca da produção de Estudos Terroristas nos Estados Unidos revela uma consolidação da figura do terrorista muçulmano durante a Guerra Fria.

${ }^{8}$ Janet Jakobsen e Ann Pellegrini também me chamaram a atenção para o facto de que aquilo que é entendido no "Ocidente" como secularismo ser inerentemente informado pelos condicionamentos ideológicos Cristãos. Ou seja, aquilo que é definido como secular decorre da absorção das normas Cristãs como seculares, desde a contagem do tempo até à economia consumista das férias, passando pelos fundamentos teológicos implícitos da moralidade sexual. Aquilo que Jakobsen e Pellegrini insinuam, então, é que não existe um posicionamento secular puro, pelo menos nos Estados Unidos; o secularismo já é contraindicado pela orientação religiosa que procura repudiar. Devo, ainda, acrescentar que a reivindicação de um posicionamento puro deste género, neste momento político específico, parece ser mais perturbadoramente aplicado relativamente às expressões públicas da crença Islâmica. O que deverá levar-nos a perguntar: é secular ou é racista? Onde e quando é que os termos do secularismo são tomados e ativados como forma dissimulada de racismo cultural? Ver Jakobsen, J. \& Pellegrini, A. (2003). Love the sin: sexual regulation and the limits of religious tolerance.

9 Ver Faderman L. \& Rothstein, R. (2011). A new state for homophobia. The advocate, L. Oct. 12, disponível em http:// www.advocate.com/politics/commentary/2011/10/12/op-ed-new-state-homophobia; Palestine: Lillian Faderman Responds to Alex Blaze, the bilerico Project (12 de outubro de 2011), disponível em http://www.bilerico.com/2011/10/palestine_liIlian_faderman_responds_to_alex_blaze.php.
} 
mas e o facto de serem tão sexistas e homofóbicos? Contudo, em TA, observo, não só a proliferação do nível de queer enquanto norma branca, Cristã, secular, mas também a proliferação do homonacionalismo nas comunidades queer Árabes muçulmanas e do Sul Asiático ${ }^{10}$ nos Estados Unidos, pelo que não se trata simplesmente de uma crítica das exclusões raciais e da incidência de brancos nas comunidades LGBT dominantes."

Dois dos exemplos mais recentes de homonacionalismo nos Estados Unidos são dolorosamente ilustrativos das violências assimétricas dos discursos sobre os direitos. A proibição de homossexuais nas forças militares dos Estados Unidos - a política “Don't Ask Don't Tell” - foi revogada no dia 18 de dezembro de 2010, no mesmo dia em que o Senado dos Estados Unidos pôs termo à lei DREAM (Development, Relief, and Education for Alien Minors), uma legislação que teria legalizado milhões de estudantes ilegais, permitindo-lhes aceder ao ensino superior e, ironicamente, listar-se nas forças militares. No final de 2009, foi aprovada a lei Mathew Shepard James Byrd Hate Crimes Prevention (a primeira legislação federal a criminalizar crimes de ódio contra pessoas gays, lésbicas e transexuais), ironicamente, em grande medida, por estar associada a um projeto de recursos militares. ${ }^{12}$ Isto mostra o progresso queer que não apoia a guerra contra o terrorismo.

Mas mesmo antes de se saber que a proposta estava a ser manipulada para reforçar os fins militaristas, as pessoas queer de organizações de pessoas de cor, como a "Audre Lorde Project" e vários membros de grupos com elas relacionados, como a "Queers for Economic Justice", emitiram um comunicado manifestando-se contra a suposta aprovação "histórica" da legislação contra crimes de ódio, alegando que a intervenção jurídica seria de tal modo perniciosa que seria melhor não criminalizar estes crimes de ódio específicos. ${ }^{13}$ Estas organizações defendiam que a legislação contra os crimes de ódio conferia mais recursos para a "militarização" das forças policiais e para a perseguição e vigilância administrativa de pessoas de cor (sobretudo as pessoas de cor mais jovens, consideradas a priori como sendo mais homofóbicas do que os seus colegas brancos), sobretudo Latino-americanos e Afro-americanos, cujos números desproporcionais de detenção nos Estados Unidos são conhecidos. ${ }^{14}$

De um ponto de vista histórico, nos Estados Unidos estas populações não têm podido confiar na proteção do Estado e da Polícia contra a violência; antes, têm sido alvo da violência destes sistemas alegadamente de proteção. Além disso, novas populações

\footnotetext{
${ }^{10}$ É aqui que o secularismo Hindu e o nacionalismo indiano convergem virulentamente.

"O meu interesse no entrosamento biopolítico do nível de queer e de nacionalismo iniciou-se com a minha investigação de tese em Trindade, nos anos 9o, na qual estudei as tensões entre afro e indo-trindadianos no movimento gay e lésbico, e continuou com a minha investigação sobre turismo gay e lésbico, entendendo a produção da diferença entre nações simpatizantes gay e não simpatizantes gay como sendo endémicas da integração neoliberal dos consumidores queer.

12 SRLP Sylvia Rivera law Project. On hate crime laws. Disponível em http://srlp.org/our-strategy/policy-advocacy/hate-crimes / (último acesso em 15 de maio de 2013) ("Esta lei em particular estava associada a uma medida de 680 mil milhões de dólares para o orçamento do Pentágono, incluindo 130 mil milhões de dólares para continuação das operações militares no Iraque e no Afeganistão").

${ }^{13}$ Ver A compilation of critiques on hate crimes legislation, blackandPink.org, disponível em http://www.blackandpink.org/ revolt/a-compilation-of-critiques-on-hate-crimes-legislation (último acesso em 15 de setembro de 2013).

14 Ver Gilmore, R. (2007). The golden gulag: prisons, surplus, crisis, and opposition in globalizing California.
} 
unem-se através da recolha de dados estatísticos, demográficos, financeiros e informações pessoais, com o objetivo de deslocarem aqueles que são vistos como alvos dos crimes de ódio para o âmbito da produção de conhecimento, de modo a tornarem-se "objetos" da vigilância do Estado sob o suposto pretexto de serem "sujeitos" da proteção do Estado. Estas preocupações cautelosas relativamente à eficácia limitada da intervenção jurídica foram totalmente ignoradas pelas organizações nacionais de gays e lésbicas dominantes, organizações essas que também não criticaram nem comentaram a legislação relativamente às graves cedências realizadas para permitir a sua aprovação. ${ }^{15}$

Uma vez que o TA não tinha objetivos corretivos, mas antes pretendia incentivar um debate produtivo e construtivo, tem sido arrebatador e inspirador ver como o "homonacionalismo" enquanto conceito tem sido desenvolvido, adaptado, rearticulado e criticado em diversos contextos nacionais, ativistas e académicos na América do Norte, na Europa, no Médio Oriente e na Índia. Um grupo sediado em Paris, designado "Não ao Homonacionalismo" (Non a l'homonationalisme) está a contestar a campanha promocional proposta para o Gay Pride, em Paris, que utiliza o símbolo nacional do galo branco. ${ }^{16}$ Uma conferência sobre Democracia Sexual em Roma pôs em causa a organização do World Pride na zona da cidade com mais imigrantes, reclamando uma política queer secular que desafia o Vaticano, bem como o homonacionalismo das entidades organizadoras europeias. ${ }^{17} \mathrm{Em}$ abril de 2013, o Center for Lesbian and Gay Studies (CLAGS) do CUNY Graduate Centeruma organizou uma conferência internacional de dois dias sobre "Homonacionalismo e lavagem cor-de-rosa". ${ }^{18}$

Apesar de eu trabalhar sobretudo nos Estados Unidos, em TA baseei-me em exemplos da Grã-Bretanha e da Holanda para ilustrar o trabalho das narrativas de progresso liberal, exemplos esses que vão além das figuras políticas anti-imigração gays de direita, que estão a conquistar uma importância cada vez maior em vários países da Europa. $\mathrm{Na}$ Europa, continuam a proliferar estas tensões entre as organizações e os discursos dos direitos liberais e os grupos queer de organizações antirracistas, de pessoas de cor, e de estudiosos queer de cor. Em junho de 2010, Judith Butler recusou o Civil Courage Award que Ihe foi atribuído pela Christopher Street Day Parade, em Berlim, devido à história de posicionamento anti-imigração da organizaçã. ${ }^{19} \mathrm{O}$ controverso incidente revelou a incapacidade das organizações queer liberais para questionarem as suas práticas de perfil racial e as suas crenças enraizadas sobre as normas seculares brancas

\footnotetext{
${ }^{15}$ Para ler na íntegra as negociações legislativas realizadas e conhecer os pormenores do projeto de lei, ver Reddy, C. (2011). Freedom with violence: race, sexuality and the US state.

${ }^{16}$ Liberation of Homosexual Muslims of France, Beyond Islamophobia and anti-Semitism, Homonationalism, disponível em http://www.homosexuels-musulmans.org/__HOMONATIONALISM__Liberation-of-homosexual-Muslims-of-France-beyond-Islamophobia-and-anti-Semitism. html.

17 In and out of sexual democracies, Facciamo Breccia, (23 de março de 2011), disponível em http://www. facciamobreccia. org/content/view/516/ (mais informações sobre o congresso).

${ }^{18}$ Homonationalism and Pinkwashing Conference, The Centre for Lesbian and Gay Studies (10-11 de abril de 2013), disponível em http://homonationalism.org/

19 Puar, J. (2010). Celebrating refusal: the complexities of saying no, bully bloggers. Disponível em http:// bullybloggers.wordpress.com/2010/06/23/celebrating-refusal-the-complexities-of-saying-no/\#comments
} 
da homossexualidade. Também realçou a tendência generalizada para "citar no sentido ascendente", em vez de "citar no sentido descendente" ou abordar o tema expansivamente, lateralmente, ecleticamente, uma vez que o estatuto de celebridade de Butler apresentava um interesse maior do que os grupos queer antirracistas que ela destacava na sua rejeição pública e do que os académicos que a apoiavam na sua crítica. ${ }^{20}$ Já houve duas tentativas (relativamente bem sucedidas) do autoproclamado principal ativista de direitos humanos de gays e lésbicas britânico, Peter Tatchell, do grupo queer "OutRage!", para reprimir a crítica legítima ao seu trabalho e à sua política. Os artigos "Gay Imperialism", de Jin Haritaworn, Tamsila Tauqir e Esra Erdem², e "Unbearable Witness", de Scott Long ${ }^{22}$, anteriormente pertencentes à Human Rights Watch, foram retirados e retratados na sequência de ameaças jurídicas implícitas e explícitas de Tatchell, que, infelizmente, se encontra protegido pela arcaica legislação de difamação do Reino Unido, segundo a qual o acusado é presumível culpado, salvo prova em contrário. ${ }^{23}$

Pouco tempo antes de regressar à Índia, tive oportunidade de ver I Am, um bonito documentário passado em Nova Deli e de fazer a ronda pelo circuito global do festival de cinema gay e lésbico. ${ }^{24} \mathrm{O}$ conceito subjacente a I Am é simultaneamente profundamente pessoal e político. A realizadora de cinema Sonali Gulati (de Nova Deli, atualmente a residir nos Estados Unidos) faz o luto ao falecimento da sua mãe, perante quem nunca teve oportunidade de "sair do armário" relativamente ao seu desejo de "casar com uma mulher". O filme termina com cenas das comemorações em Deli após a leitura da Sec.

\footnotetext{
${ }^{20}$ Ver id. (Também gostaria de indicar o website "No Homonationalisms" (nohomonationalism.org) para uma explicação mais pormenorizada sobre a apropriação e exploração da cor em práticas académicas de citação. Devo acrescentar que a decisão de Butler em recusar o prémio foi igualmente repudiada por muitas pessoas que se pensaria serem "aliados naturais". Por outras palavras, as organizações queer dominantes foram indiferentes às suas críticas.)

${ }^{21}$ Haritaworn, J. et. al. (2008). Gay imperialism: gender and sexuality discourse in the 'War on Terror'. In Adi Kuntsman \& Esperanza Miyake (Eds.), Out of Place: Interrogating Silences in Queerness/Raciality (pp. 9-33). (o pedido de desculpas a Peter Tatchell encontra-se disponível em http://www. rawnervebooks.co.uk/outofplace.html); Ver também Ahmed, S. (2011) Problematic proximities: or why critiques of gay imperialism matter. Fem. Legal Studies, 19 (2), 119-32.

${ }^{22}$ Long, S. (2009). Unbearable witness: how western activists (mis) recognize sexuality in Iran. Contemp. Pol., 15 (1), 11 9-36.

${ }^{23}$ Estas práticas de citação violentas e de censura de análises discordantes ou "desagradáveis" são extraordinária e incrivelmente danosas para os tipos de comunidades positivas, construtivas, intelectuais, sociais e políticas que todos procuramos apoiar. Não só nos arriscamos a reproduzir um cânone (queer) defensivamente branco, como também, mais proativamente, as práticas de citação podem constituir uma forma de redistribuição de recursos que permite questionar a lógica neoliberal de compartimentalização e hierarquia, e disciplinaridade, ao desviarem a nossa atenção noutro sentido. Mas de forma mais violenta, estas práticas continuam a reiterar o binário descomplicado de queers, feministas e outros liberais seculares brancos - e mais uma vez seculares Cristãos -, que continuam a agir com impunidade relativamente às formas liberais de racismo que condenam, ao mesmo tempo que exigem a responsabilização dos Outros raciais e religiosos pela homofobia e sexismo considerado desenfreado nas suas comunidades de origem. Deste modo, os binários nunca dizem respeito a uma relação entre dois atores em situação de igualdade, como sabemos. Em caso de "citação descendente" (como forma de expor as realidades hierárquicas) ou mesmo "citação lateral", i.e. citação expansivamente praticada mais integralmente no nosso trabalho, poder-se-ia constatar que o trabalho de atacar a homofobia nas comunidades religiosas e raciais continua inalterado. Seria extremamente útil ir além desta questão para obter mais informações sobre a forma de realização deste trabalho, porque, caso contrário, nunca passaremos de um modo de chamada e resposta. O que ocorre é simplesmente - como presenciei no congresso "Sexual Nationalisms", em Amesterdão, - um re-centramento dos traços queer seculares brancos e das suas ansiedades relativamente aos Outros Raciais, a maior parte dos quais estava presente in absentia. Esta infinita autorreferencialidade da crítica pós-estruturalista é aquilo a que Rey Chow se refere como "encarceramento significativo pós-estruturalista." Chow, R. (2006). The age of the world target: self- referentiality in war, theory, and comparative work, p. 53
}

${ }^{24}$ I Am, filme de Sonali, disponível em http://www.sonalifilm.com/l-AM.html. 
377. Portanto, o filme assenta, desde logo, nas duas questões mais centrais daquilo que é conhecido nos Estados Unidos como "agenda de igualdade gay": a descriminalização da sodomia e o casamento homossexual. A progressão narrativa que orienta a história é codificada através do tropo "sair do armário", que permanece um desejo estável e não irónico, apesar de ter sido amplamente criticado por teóricos e ativistas queer do sul da Ásia devido ao seu episteme ocidental. ${ }^{25} \mathrm{O}$ filme realça, sobretudo, várias mulheres lésbicas que são percebidas como sendo masculinas, muitas das quais fazem parte de uma "classe ativista transnacional" de trabalhadores envolvidos na luta pelos direitos de gays e lésbicas. Gulati fundamenta os conflitos que surgem na procura de aceitação familiar. No final, a maioria dos pais indianos transforma-se em apoiantes bons, liberais e tolerantes dos seus filhos e filhas homossexuais.

I Am está agora a ser utilizado em Nova lorque pela SALGA (South Asian Lesbian and Gay Association), a Associação de Gays e Lésbicas do Sul da Ásia, para promover a tolerância e a aceitação dos filhos homossexuais pelos pais no Sul da Ásia. Não há dúvida de que a adoção de I Am nos Estados Unidos como modelo de aceitação familiar foi, em parte, motivada pela série de "suicídios de jovens gays" que ocorreu no final de 2010. ${ }^{26}$ Porém, para promover uma verdadeira agenda queer não nacional, devemos ser críticos, não só relativamente à homofobia familiar, como também ao próprio modelo de família — inclusivamente da família queer. A noção de família queer — "famílias que escolhemos" 27 — pode muito bem convidar objetos novos e validar objetos diferentes para o discurso da família, mas a direcionalidade do afeto familiar e da reprodução física pode perfeitamente ser a mesma. Ou seja, os objetos e os sujeitos da família podem mudar, mas os problemas inerentes à reprodução heteronormativa - e, nestes casos, à reprodução homonormativa - não se dissipará simplesmente com uma alteração da escolha do objeto, como vimos vezes sem conta no caso dos limites impostos pelas agendas da igualdade gay.

Como acontece nos Estados Unidos, será o casamento homossexual o ponto que se segue na agenda da igualdade gay na Índia? Quem é que sai a ganhar com uma agenda para a igualdade dos direitos homossexuais centrada no casamento? Existe alguma relação entre a aprovação da Sec. 377 , que assinala um movimento LGBT de classe média cada vez mais visível na Índia, e a natureza e visibilidade da violação sexual de muIheres, como é o caso da recente violação coletiva e assassinato que ocorreu em Nova Deli, em dezembro de 2012? Estarão as mulheres que transgridem as posições que lhes são destinadas em termos de binário de género a ser punidas através de uma violenta reação contra a luta pela libertação sexual?

A respeito da Sec. 377, afirma Oishik Sircar:

\footnotetext{
${ }^{25}$ Ver, e.g., Ratti, R. (Ed.) (1993). A lotus of another color: an unfolding of the south asian gay and lesbian experience; Shah, N. (1998). Sexuality, identity, and history. In David L. Eng \& Alice Y. Hom (Eds.). QQA: Queer in Asian America; Puar, J. (1998). Transnational sexualities: South Asian (trans)nation(alism)s and queer diasporas. In David L. Eng \& Alice Y. Hom (Eds.), QQA: Queer in Asian America (on South Asian queer transnationalisms).

${ }^{26}$ Ver Puar, J. (2012). The cost of getting better: suicide, sensation, switchpoints. GLQ: J. of Lesbian Q Gay Studies, 18 (1), 149-58.

${ }^{27}$ Ver Weston, K. (1997). Families we choose: lesbians, gays, kinship.
} 
A descriminalização das relações entre pessoas do mesmo sexo é claramente um resultado do aumento gradual da aceitação cultural de diferentes sexualidades decorrente da liberalização e da globalização, como evidenciam as alusões constantes do tribunal à legislação internacional de direitos humanos e à jurisprudência, e a precedentes sobretudo nos Estados Unidos. Estas referências revelaram a lógica cultural por detrás do julgamento do tribunal: a Índia necessita de acompanhar os desenvolvimentos progressivos de outras partes do mundo (ocidental), descriminalizando a sodomia. Como referiu Anjali Gopalan, fundadora da peticionária Naz Foundation, após o desfecho do julgamento, "Oh meus Deus, passámos finalmente para o século XXI." Esta exclamação parece constituir um momento de ofuscação da história, em que o presente ostensivamente progressista contribui para a emancipação queer, ao mesmo tempo que nos cega relativamente à compreensão historizada das genealogias cruelmente liberais da Índia contemporânea. ${ }^{28}$

Em vez de sugerir que estas aspirações à entrada no século XXI, proclamadas por Gopalan, ${ }^{29}$ constituem simplesmente versões de homonacionalismo aplicadas ao caso indiano, será mais prudente notar as divergências e as diferenças que suscitam tipos diversificados de homonacionalismo. O que é crucial para uma/a luta política contínua em diversos locais não é criticar um muito aguardado filme orientado para a comunidade ou os esforços de ativistas gays e lésbicas em qualquer zona do território nacional, mas sim insistir numa notoriedade do homonacionalismo como um processo desequilibrado e imprevisível. Em que medida é que a história do colonialismo britânico, a periodicidade específica da liberalização na Índia e a aceitação da estratificação de classes neoliberal, produtora de redes transnacionais privilegiadas, dão forma ao homonacionalismo como mosaico?

\section{2. “LAVAGEM COR-DE-ROSA" ISRAELITA NUM MUNDO CADA VEZ MAIS HOMONACIONALISTA}

Acompanhando o movimento de homonacionalismo como mosaico no seu questionamento da periodização e do progresso, esta secção apresenta uma discussão daquilo que ficou conhecido como lavagem cor-de-rosa, ou a prática de encobrimento ou distração das políticas de discriminação de algumas populações de um país através de um pregão ruidoso dos seus direitos gays apenas para um grupo restrito..$^{30}$ Foco, aqui, a

\footnotetext{
${ }^{28}$ Sircar, O. (2012). Spectacles of emancipation: reading rights differently in India's legal discourse. Osgoode Hall I. J., 49 (3), 563 .

${ }_{29}$ Flock, E- (2009, Dec. 26). The law breaker. Forbes India. Disponível em http://business. in.com/printcontent/8082.

30 Em 11 de janeiro de 2011, Tel Avive foi eleita a "melhor cidade gay do mundo" do ano, numa sondagem da gaycities.com, ultrapassando Londres, Toronto e Nova lorque, entre outras cidades cosmopolitas. Nesse mesmo dia, a nossa delegação de solidariedade LGBTIQ na Palestina - a primeira de sempre do género - reunia-se com várias organizações ativistas contra a ocupação israelita, incluindo a Boycott from Within, a Anarchists Against the Wall e a Zocheot, um projeto em memória de Nakba. Um dos nossos porta-vozes mostrou as complexidades com que nos defrontamos ao fazer com que a anti-ocupação, boicotes, desinvestimento e sanções funcionem quando se está na boca do lobo, ou seja, em Israel, referindo sarcasticamente: "Portanto, agora Tel Avive é a melhor cidade gay. Também é a cidade menos Árabe do mundo. É extraordinariamente raro ouvir falar Árabe nas ruas de Tel Avive."
} 
Palestina/Israel por duas razões: em primeiro lugar, porque, a seguir aos Estados Unidos, Israel é, em minha opinião, o maior beneficiado com o homonacionalismo, por motivos que se prendem, em parte, com o seu entrosamento com os Estados Unidos, mas não só; e, em segundo lugar, porque o Estado de Israel foi acusado de fazer "lavagem cor-de-rosa" de modo aparentemente distinto de qualquer outro país, e não estou convencida de que a lavagem cor-de-rosa seja uma prática exclusiva do Estado israelita. Muito simplesmente, a lavagem cor-de-rosa foi definida como a utilização, pelo estado israelita, do seu excelente historial de direitos LGBT como forma de desviar as atenções e, nalguns casos, justificar ou legitimar, a sua ocupação da Palestina. Desenvolvendo o pensamento num campo recetivo de islamofobia globalizada significativamente alargada desde 011 de setembro, e assente numa narrativa civilizacional acerca da modernidade dos israelitas, em contraste com a homofobia retrógrada dos Palestinianos, a lavagem cor-de-rosa tornou-se um rótulo utilizado com frequência para referir a promoção cínica dos organismos LGBT como sendo representativos da democracia israelita. Como tal, funciona como uma forma de titularização precoce discursiva.

Por que é que a lavagem cor-de-rosa tem leitura e é persuasiva enquanto discurso político? Em primeiro lugar, uma estrutura económica neoliberal acomodacionista cria o marketing de nicho de diversos grupos éticos e minoritários, normalizando a produção de uma indústria do turismo gay e lésbico assente na distinção discursiva entre destinos simpatizantes gay e destinos não simpatizantes gay. A maior parte dos países que aspiram a formas de modernidade ocidental ou europeia possui, atualmente, campanhas de marketing de turismo gay e lésbico. Neste sentido, Israel está a fazer o mesmo que outros países e aquilo que é pedido pela indústria do turismo gay e lésbico: a promover-se a si mesmo. Poderemos, naturalmente, notar que os efeitos desta promoção são profundamente prejudiciais, no caso da ocupação. Mas poderemos colocar algumas questões acerca das especificidades da "Brand Israel Campaign", a campanha da marca Israel que foi posicionada como a fonte da lavagem cor-de-rosa de Israel. Em que medida é que a Brand Israel Campaign diverge de uma campanha publicitária convencional patrocinada pelo Estado, e destinada a turistas gays e lésbicas? ${ }^{31}$

Além disso, em alguns sentidos, Israel é pioneiro do homonacionalismo, uma vez que a sua posição particular no cruzamento do colonialismo, da ocupação e do acomodacionismo neoliberal proporciona as condições perfeitas para a normalização da homossexualidade. A história homonacionalista de Israel ... a ascensão dos direitos LGBT em Israel e o aumento da mobilidade para gays e lésbicas - desenvolve-se em paralelo com o aumento simultâneo da segregação e a diminuição da mobilidade das populações Palestinianas, sobretudo pós-Oslo.32 Descrevi este aspeto mais pormenorizadamente noutro estudo, mas, resumindo rapidamente: o surgimento dos direitos gays em Israel teve início mais ou menos ao mesmo tempo que a primeira Intifada, tendo os anos 90 ficado conhecidos como a "década gay" de Israel, direitos esses que foram assegurados

\footnotetext{
${ }^{31}$ Ver Schulman, S. A Documentary Guide to Pinkwashing, PrettyQueer, Disponível http://www.prettyqueer.com/2011/11/29/a-documentary-guide-to-pinkwashing-sarah-schulman-new-york-times-oped/ (para a sua descrição da Brand Israel).

${ }^{32}$ Ver Stein, R- (2010). Explosive: scenes from Israeli queer occupation. GlQ: J. Lesbian Q Gay Studies, 16 (4), 517-536.
} 
pela legalização da homossexualidade nas forças militares de Israel, pelas disposições anti-discriminação no local de trabalho e muitas outras alterações legislativas. ${ }^{33}$

A lavagem cor-de-rosa funciona através de uma supressão da lógica espacial do controlo da Ocupação e do intrincado e, inclusivamente, íntimo sistema de apartheid, repleto de uma vertiginosa série de obstáculos localizacionais à mobilidade Palestiniana. O facto de os ativistas palestinianos queer em Ramallah não poderem viajar para Haifa, em Jerusalém, ou para Gaza para se encontrarem com os colegas ativistas palestinianos parece ser uma das ilustrações mais óbvias de como a ocupação israelita circunscreve (na realidade, proíbe) as possibilidades de florescimento de organizações e comunidades queer de que os israelitas desfrutaram sem quaisquer problemas.

Em vez de compreender o acesso à mobilidade e a congregação como parte integrante da comunidade e da identidade queer, e de reconhecer os limitadores e sufocantes efeitos espaciais e económicos do apartheid, a lavagem cor-de-rosa reforça as ideologias de choque de culturas e a "diferença cultural" da homofobia palestiniana. As questões acerca do tratamento de homossexuais na Faixa Ocidental ou na Faixa de Gaza não levam em conta as constantes e omnipresentes restrições à mobilidade, ao contacto e à organização necessárias à construção de qualquer tipo de presença e política queer. O que se torna claro é que a suposta preocupação com o estatuto dos homossexuais na Faixa Ocidental e na Faixa de Gaza está a ser utilizada para proteger a Ocupação contra a culpabilização direta pela supressão desses mesmos homossexuais, na realidade colocando-os em perigo. Além disso, o próprio projeto dos direitos LGBT assenta na impossibilidade/ausência/não reconhecimento de um sujeito queer palestiniano adequado, exceto no âmbito do próprio Estado israelita, que apresenta o "paraíso gay" de Tel Aviv34 como representativo de todo o país, e isento de qualquer escrutínio relativamente à sua limpeza árabe, ao mesmo tempo que mantém Jerusalém como salvaguarda religiosa.

Uma vez que a sua utilização abreviada prolifera nos fóruns de organizações anti-ocupação internacionais, a lavagem cor-de-rosa deve ser situada no seu contexto geopolítico homonacionalizador mais alargado. Ou seja, se a lavagem cor-de-rosa for eficaz, não será graças a uma extraordinária atividade egrégia por parte do governo israelita, mas antes porque a história e as relações internacionais globais são importantes. Portanto, embora seja crucial questionar o Estado israelita, isso deve fazer-se de um modo que reconhece que o mosaico do homonacionalismo vai além das atividades explícitas de qualquer Estado-nação, incluindo Israel. Sustentando-me em aspetos teóricos explorados inicialmente em $T A$, defendo que é crucial ter em mente que a lavagem cor-de-rosa parece ser uma estratégia eficaz, não necessariamente devido a quaisquer atividades excecionais por parte do Estado israelita, mas por causa da história de violência dos colonizadores, da indústria do turismo LGBT internacional, da indústria dos direitos humanos de gays e lésbicas e, finalmente, do papel dos Estados Unidos.

33 Ver Puar, J. (2011). Citation and Censorship: The Politics of Talking About the Sexual Politics of Israel. Fem. Legal stud, 19 (2), $133-42$.

34 Hartman, B. (2011, 1 nov.). Tel Aviv named 'world's best gay city' for 2011, Jerusalem Post, disponível em http://www.jpost. com/LifeStyle/Article. aspx?id=253121. 
A lavagem cor-de-rosa é apenas mais uma justificação para a violência imperial/ racial/nacional que é precedida por uma longa história. De que modo é que "a questão homossexual" veio complementar "a questão da mulher" da era colonial, no sentido de modular a arbitragem entre a modernidade e a tradição, entre o cidadão e o terrorista, entre o homonacionalista e o queer? Conforme descrito por Partha Chatterjee, esta questão surgiu com alguma pujança nos movimentos de descolonização do Sul da Ásia e de outros locais, através dos quais a capacidade de um governo pós-colonial emergente para proteger as mulheres nativas das práticas culturais patriarcais opressivas, assinalada como tradição, se tornou o barómetro através do qual a regra colonial arbitrou as concessões políticas feitas aos colonizados. ${ }^{35}$ Por outras palavras, ensaiamos aqui o famoso ditado de Gayatri Spivak "homens brancos a salvar mulheres negras dos homens negros." 36

Esta triangulação em particular abriu, assim, caminho a um drama duradouro entre feministas, que protestam contra os regimes coloniais e neocoloniais, e nacionalistas, que ignoram a presença e a política dessas feministas na sua própria procura de descolonização. Também podemos dizer que, embora a questão da mulher mal tenha desaparecido, é agora acompanhada por aquilo que poderíamos designar por questão homossexual - na realidade, mais uma variante ou operação de homonacionalismo. Os termos da questão da mulher foram reformulados, com as estudiosas feministas a tornarem-se agora árbitros das modernidades de outras mulheres, ou das modernidades de A Outra Mulher. Invocando novamente Spivak, mas no âmbito do século XXI: (homens) queer brancos a salvar homossexuais negros dos heterossexuais negros.

Podemos observar de que modo se passa da questão da mulher para a questão do homossexual, faltando ainda contextualizar, nas várias localizações, quais destas trajetórias fazem mais ou menos sentido. Em primeiro lugar, a complementaridade da homossexualidade face às mulheres resulta da fusão de dois processos: o estado pós-colonial que apoia a respeitabilidade e a legitimidade como forma de provar o seu direito à soberania do pai colonia| ${ }^{37}$ e a introdução lenta ou a aceitação dos sujeitos homossexuais na legitimidade jurídica e de consumo através das economias neoliberais, de tal modo que os homossexuais, outrora do lado da morte (SIDA), se encontram agora do lado da vida ou são produtivos na construção na nação. Em segundo lugar, a questão homossexual constitui, de facto, uma reiteração da questão da mulher, na medida em que reproduz uma procura de excecionalismo de género e que se baseia na reprodução continuada do binário de género. Os homossexuais vistos a serem tratados devidamente pelo Estado-nação não são "queer de género". Antes, são aqueles que recriam normas genderizadas através da identidade homossexual, e não apesar da mesma. Escondidos pela lavagem

\footnotetext{
35 Chatterjee, P. (1990). The nationalist resolution of the women's question. In Kumkum Sangari \& Sudesh Vaid (Eds.), Recasting Women: Essays in Colonial History (pp. 233-253).

${ }^{36}$ Spivak, G.C. (1988). Can the subaltern speak?. In Lawrence Gossberg \& Cary Nelson (Eds.), Marxism and the Interpretation of Culture (pp. 271-313).

37 Ver Alexander, M. (1994). Not just (any) body can be a citizen: the politics of law, sexuality and postcoloniality in trinidad and tobago and the Bahamas. Fem. Rev, 48, 5-23.
} 
cor-de-rosa, os transexuais e os queers não-conformistas ao género não são bem-vindos nesta nova versão do cidadão "homonacionalista" israelita pleno. ${ }^{38}$

Também turvada pela lavagem cor-de-rosa encontra-se a constante minimização da questão da mulher relativamente à questão homossexual quando associada sobretudo a corpos masculinos, brancos, do primeiro mundo, como é o caso de Israel (por exemplo, os debates sobre a segregação de género nas comunidades ultraortodoxas de Israel ainda estão por iniciar). Eis outro exemplo de como a questão homossexual fere a questão da mulher: no dia 11 de janeiro de 2011, no mesmo dia em que foi anunciada a dúbia menção honrosa de Tel Aviv como "melhor cidade gay do mundo", foi aprovada, pelo Supremo Tribunal de Justiça, a alteração da legislação de cidadania de Israel, que proíbe a união entre os palestinianos da Faixa de Gaza e os seus cônjuges em Israel. ${ }^{39}$ Junte-se a isso a aprovação da legislação de "adequação social"40, as tentativas de regulação das atividades sexuais entre trabalhadores estrangeiros e Judeus israelitas, grupos de "vigilantes" e organizações sociais que supervisionam e agem contra as relações sexuais entre mulheres judaicas israelitas e homens palestinianos, e torna-se evidente que a libertação LGBT também é uma forma de desviar as atenções das intensas formas de regulação (heteros)sexual, regulação essa que procura restringir as atividades sexuais, reprodutoras e familiares de todos os corpos que não são considerados adequados à política do corpo israelita. A lavagem cor-de-rosa não só opera, assim, através de uma representação ativa da população palestiniana como sendo homofóbica ou anti-homofóbica, como também o alvo biopolítico consiste sem dúvida em controlar ainda mais a reprodução heterossexual, sobretudo entre palestinianos e Judeus israelitas. ${ }^{41}$

Os organizadores queer palestinianos argumentam que o facto de a sociedade palestiniana ser ou não ser homofóbica é irrelevante, e que a questão da homofobia na sociedade palestiniana não está relacionada com o facto de que a Ocupação tem de acabar. Para a pujante plataforma política dos "Palestinian Queers for Boycott, Divestment and Sanctions" (doravante referida como PQBDS) e dos "Al-Qaws for Sexual and Gender Diversity in Palestinian Society" (doravante referida como Al-Qaws), a organização queer é uma organização anti-ocupação, tal como o trabalho anti-ocupação constitui organização queer. A Palestinian Queers for BDS não é um projeto liberal que exige a aceitação, a tolerância ou a inclusão num movimento "nacionalista"; antes, ao destacar a ocupação

\footnotetext{
$3^{38}$ Ver Solomon, A. (2003). Viva la diva citizenship: post-zionism and gay rights. In Daniel Boyarin et. al. (Eds.), Queer Theory and the Jewish Question (pp. 149-65).

39 Puar, J. (2012, jan. 30). The golden handcuffs of gay rights: how pinkwashing distorts both lgbt and anti-occupation activism, Fem. Wire, disponível em http://thefeministwire. com/2012/o1/the-golden-handcuffs-of-gay-rights-how-pinkwashing-distorts-both-Igbtiq- and-anti-occupation-activism/; Ben Hartman, supra nota 33; Izenberg, D. \& Stoil, R.. High Court rejects petition against citizenship law. Jerusalem Post, http://www. jpost.com/Diplomacy-and-Politics/High-Court-rejects-petition-against-citizenship-law (última atualização 1 de novembro de 2012).

$4^{\circ}$ Sanders, E. (2011, mar. 24). New israeli laws will increase discrimination against arabs, critics say. L.A. Times, disponível em http://articles.latimes.com/2011/mar/24/world/la- fg-israel-arab-laws-20110324; Social suitability' nears ok as israeli housing criterion. Israel Religious Action Center, disponível em http://www.irac.org/NewsDetailes.aspx?ID=846 (última consulta em 15 de setembro de 2013).

${ }^{41}$ Puar, J. (no prelo 2014). Affective politics: states of debility and capacity (esta linha de argumento serve de prefácio a um capítulo sobre sexo, direitos de reprodução e deficiência na Palestina/ Israel no meu livro, que se encontra no prelo).
} 
como seu principal local de luta, a PQBDS, lenta, estratégica e cuidadosamente, insiste e introduz mudanças sistémicas e profundas nos termos da própria sociedade palestiniana. A Al-Qaws defende que a vertente principal do seu trabalho consiste em acabar com a ocupação, e não em reificar uma identidade homossexual que reflete uma forma oportunista de liberdade sexual "israelita" ou "ocidental". ${ }^{42}$

Trata-se de uma tática importante no contexto de uma indústria dos direitos humanos de gays e lésbicas que fazem proliferar os constructos de identidade euro-americanos (para não falar do pressuposto de uma ligação universal à própria identidade sexual), que privilegia a política de identidade, a "saída do armário", a visibilidade pública, as medidas legislativas como barómetros dominantes do progresso social, e uma invocação linear da "homofobia" como um enquadramento automático, unificador, experiencial. Neste sentido, embora possamos discordar da crítica negativa de Joseph Massad à "Gay International", seria conveniente perguntar exatamente em que medida é que a "Queer International" proposta por Sarah Schulman constitui uma alternativa ou um antídoto para a Gay International. ${ }^{43}$ Será simplesmente pelo facto de ser articulada através de "queer", em vez de "gay", e através de um movimento global de solidariedade, que se evitam efetivamente as armadilhas da Gay International? E em que medida é que isso consiste um posicionamento de "queer", um posicionamento que se supõe transgressivo, moral e politicamente imaculado, e fora dos círculos de poder?

A lavagem cor-de-rosa é, assim, aquilo que Michel Foucault designou um "incitamento ao discurso" 44 , uma forma impelente de confessionalismo instaurador de um circuito de chamada e resposta que proclama a própria identidade criticada por ser impossível. Rejeitando a resposta liberal a este incentivo ao discurso - uma versão contemporânea de "Estamos aqui, somos queer, habituem-se" - sugere que possamos não pretender responder à lavagem cor-de-rosa como (sobretudo ou apenas) queers, uma vez que essa resposta reforça a lógica identitária de um único eixo da lavagem cor-de-rosa que isola a identidade "queer" das restantes identidades. Nem a lavagem cor-de-rosa é uma questão queer per se, nem mesmo uma que utiliza os queers especificamente para procurar atingir os objetivos do Estado. A lavagem cor-de-rosa não é, de forma alguma, neste sentido, uma questão de identidade sexual, mas antes uma manifestação robusta da regulação da identidade num mundo cada vez mais homonacionalista - um mundo que avalia a pertença nacional com base no tratamento dos seus homossexuais. $O$ desafio, por conseguinte, consiste em não permitir que os gays liberais ou pertencentes ao sistema da zona Euro-americana (que são os principais destinatários da lavagem cor-de-rosa) desviem o guião do ativismo antilavagem cor-de-rosa da abordagem radical não liberal da PQBDS e da Al-Qaws. Em caso de fracasso desta abordagem, como explicou de forma brilhante Maya Mikdashi, a reescrita de uma política queer palestiniana radical

\footnotetext{
${ }^{42}$ Ver, e.g., http://www.alqaws.org/q/en/content/signposts-al-qaws-decade-building-queer-palestinian-discourse.

43 Entrevista de Félix Boggio Éwanjé-Épée \& Stella Magliani-Belkacem a Joseph Massad, Associate Professor, Columbia University, disponível em http://www.jadaliyya.com/pages/ index/10461/the-empire-of-sexuality_an-interview-with-Joseph; Schulman, S. (2012). Israel/ Palestine and the queer international.

${ }^{44}$ Foucault, M. (1998). The will to knowledge: History of sexuality, vol 1.
} 
através de uma política queer Euro-americana liberal representaria, de facto, um entrincheiramento ainda mais forte do homonacionalismo. ${ }^{45} \mathrm{~A}$ organização contra a lavagem cor-de-rosa através de uma plataforma "queer international" poderá, potencialmente, conduzir inadvertidamente a uma afirmação dos termos no seio dos quais o discurso da lavagem cor-de-rosa articula as suas pretensões, nomeadamente a pretensão de que a identidade queer realçada através dos direitos constitui o modo predominante através do qual as subjetividades sexuais devem ser vividas.

Em última instância, a interligação financeira, militar, afetiva e ideológica dos colonialismos dos Estados Unidos e de Israel, e o papel dos Estados Unidos, em geral, não devem ser esquecidos ao estudar os motivos pelos quais a lavagem cor-de-rosa parece ser uma estratégia discursiva eficaz. Os Estados Unidos e Israel são, diria, os principais beneficiários do homonacionalismo na ordem geopolítica global atual, uma vez que produz regimes de exceção nos registos escalares do interno, do territorial e do global. Além disso, a lavagem cor-de-rosa é, em grande medida, dirigida aos gays dos Estados Unidos - o maior apoio financeiro internacional de Israel — e, mais genericamente, aos gays Euro-americanos que possuem o capital político e os recursos financeiros para investir em Israel. As pretensões da lavagem cor-de-rosa são, muitas vezes, vistas como sendo plausíveis quando enunciadas através de um discurso dos direitos LGBT que reverbera na América do Norte e na Europa como uma medida dominante do progresso teleológico, e que faz muito menos sentido na região do Médio Oriente e do Norte de África, por exemplo, onde existe um ceticismo saudável relativamente aos discursos dos direitos LGBT e onde o conhecimento relativamente às complexidades das sexualidades na região é muito mais acentuado. Assim, o apelo da lavagem cor-de-rosa aos gays dos Estados Unidos é feito inconscientemente através da supressão do colonialismo dos Estados Unidos representado através do endosso tácito da ocupação israelita da Palestina.

\section{SEXUALIDADE, AFETO, VIRALIDADE}

Esta última secção é conjetural e especulativa. O meu objetivo, aqui, é indicar a importância do afastamento do processo de chamada e resposta que continua a basear-se na oposição de um "queer dominante/global" a um "queer-de-cor/queer não ocidental". Até ao momento, apresentei uma discussão das viagens do conceito de homonacionalismo e de que modo é que este foi adotado e, de determinada forma, reduzido a uma plataforma de organização ativista semelhante a uma crítica política do racismo e do nacionalismo em comunidades queer. Também procurei identificar as implicações da compreensão do homonacionalismo como mosaico: como uma estrutura da modernidade, uma convergência de forças geopolíticas e históricas, de interesses neoliberais de uma acumulação capitalista, quer cultural, quer material, de práticas estatais biopolíticas de controlo da população e de investimentos afetivos em discursos de liberdade, libertação e direitos. Também procurei esquematizar provisoriamente de que modo o

${ }^{45}$ Mikdashi, M. (16 de dezembro de 2011). Gay rights as human rights: pinkwashing homonationalism, jadaliypa, disponível em http://www.jadaliyya.com/pages/index/356o/gay-rights-as-human-rights_pinkwashing-homonationa. 
homonacionalismo como mosaico cria um campo global no seio do qual se desenvolve o discurso da lavagem cor-de-rosa relativamente a Israel/Palestina. A questão não é posicionar meramente Israel como um Estado homonacionalista ao qual aqueles que são antilavagem cor-de-rosa devem resistir, mas antes demonstrar o complexo mecanismo global e histórico que origina o aparecimento das atividades do Estado israelita como legítimo e progressista. Nesta secção final, discuto a sexualidade como afeto, como sensação e como parte de um mosaico de controlo biopolítico que foge a qualquer aplicação clara do homonacionalismo como conceito.

A sexualidade enquanto rede afetiva comporta um eixo de significação e um eixo de forças que não são consistentes com as designadas configurações materiais da região, configurações essas que originam expressões monolíticas como "O/A israelita (e a sua sexualidade modernista)" e "O/A palestiniano/a (e a sua sexualidade patológica)" como complementares de um humanista liberal, ainda que brutal. Pensar, quer o homonacionalismo, quer a sexualidade através de mosaicos abre o caminho a um plano ou a uma trajetória de territorialização diferente. Mesmo que a estabilidade da política do reconhecimento seja mobilizada por Israel e pelos discursos gays globais através da lavagem cor-de-rosa, a materialidade da prática sexual e da própria sexualidade é muito mais complexa, mediada e contingente do que a estagnação da política de controlo e da resistência lhes permitem.

Esta compreensão da sexualidade implica a teorização, não só de locais disciplinares específicos, mas também de técnicas mais alargadas de controlo social, tendo em conta que o "feminismo" e o "queer" e a morte ou os potenciais de vida dos seus sujeitos já foram preparados para serem produtivos em termos de governação. O debate sobre disciplina e controlo assinala uma mudança em termos da regulação da normatividade (a interiorização da formação do próprio/outro sujeito) a que Foucault chama a regularização dos corpos. Foram propostas muitas relações entre disciplina (exclusão e inclusão) e controlo (modulação, afinação): como várias fases sobrepostas, ainda que progressistas, de capitalismo de mercado e de governamentalidade; como modelos e exercícios de poder coexistentes; como um efeito de mecanismos disciplinares - controlo como personificação de uma sociedade disciplinar por excelência (na medida em que as formas de poder disciplinares extravasam os seus locais, reproduzindo-se por todo o lado); e, finalmente, disciplina como uma forma de controlo e como resposta à proliferação do controlo.

Nesta oscilação entre sociedades disciplinares e sociedades de controlo, a sexualidade é, não só comportada nos corpos, mas também dispersa por vários lugares. $\mathrm{A}$ sexualidade como modalidade afetiva é, assim, por definição não-representacionalista, uma versão distinta daquilo a que Davide Panagia chama "as formas como a sensação interrompe o senso comum" 46 . Na esteira dos "regimes de segurança" de Michel Foucault e da "sociedade de controlo" de Gilles Deleuze ${ }^{47}$, as tensões foram traçadas como

\footnotetext{
${ }^{46}$ Panagia, D. (2009). The political life of sensation, p. 2.

47 Foucault, M. (1977). Security, territory, population: lectures at the collège de France-1978; Deleuze, G. (1997). Negotiations $1972-1990$.
} 
uma passagem do (binário homo-hetero) para a diversificação, modulação e afinação (sexualidade como sensação); como locais de punição discretos (a prisão, o hospital psiquiátrico, a escola e, na Palestina, os postos de controlo que rodam e surgem aleatoriamente, e o muro de "segurança" que parece impedir sobretudo os palestinianos de chegarem às suas aldeias, às suas terras e a outros palestinianos), até regimes preventivos de titularização (podemos ver a lavagem cor-de-rosa como uma forma desta titularização preventiva ); da inclusão/exclusão até todos estão incluídos, mas como? (Ao contrário das alegações que insistem que o projeto do Estado israelita se preocupa apenas com a limpeza étnica e com a expropriação da terra, operam, neste caso, "formas de introdução" subtis, mas incisivas: apenas a título de exemplo, um palestiniano pode ter um de pelo menos 100 tipos distintos de bilhete de identidade, cada um possuindo uma microvariação face aos outros, operando aquilo que Helga Tawil-Souri descreve como "meio de poder de baixa tecnologia, visível, tátil que inclui e exclui simultaneamente os palestinianos do Estado israelita." ${ }^{48}$ ); da construção do próprio/outro sujeito/objeto até micro-estados de diferenciação; do policiamento do perfil até ao patrulhamento do afeto.

Este último ponto sobre afetos é crucial porque, enquanto a disciplina opera ao nível da identidade, o controlo opera ao nível da intensificação afetiva. Aqui sou motivada pela reformulação da sexualidade de Amit Rai como "ecologias da sensação" - como energias afetivas em vez de identidade - que transcende as designações humanistas de hetero e gay, queer e não queer, moderno e patológico. Acerca desta sexualidade, escreve Rai: guiões dominantes que normalizam, mas como modos de auto-organização que modulam e afinam. ${ }^{49}$

Podemos pensar a identidade (sexual), e as nossas ligações à identidade, como um processo que envolve uma intensificação da habituação. Ou seja, a identidade é a intensificação do hábito corporal, um "retorno para a frente" das vibrações e dos ritmos sensoriais afetivos quotidianos do corpo a um modelo disciplinar do sujeito, através do qual a sexualidade é apenas uma forma de capacidade corporal em desenvolvimento pelo capital neoliberal. Do mesmo modo, a associação agora inexata da campanha Brand Israel à lavagem cor-de-rosa constitui apenas uma entre uma série de formas de "lavagem" que compõem esta campanha. Esta habituação de intensidade afetiva ao quadro da identidade - uma relação da disciplina com o controlo, ou, na realidade, disciplinamento do controlo - comporta uma certa paragem relativamente a onde o corpo outrora se encontrava para reconciliar o local onde o corpo deve ir. É, também, uma habituação que exige determinada política e exclui uma habitação de outros.

As sensações estão, assim, sempre sob coação, nos termos de Panagia, para "fazerem sentido", com vista a submeterem-se a estes guiões dominantes, seja como

\footnotetext{
${ }^{48}$ Tawil-Souri, H. (2011). Colored identity: the politics and materiality of id cards in palestine/ israel, 107. Soc. Text, 68-69 (Suri afirma: “...o Estado israelita é acusado de tentar erradicar palestinianos e, no entanto, o Estado institui uma infraestrutura de controlo impressionante baseada na presença contínua dos palestinianos na Palestina/Israel. Contrastando com o fundo de transferência, fragmentação e eliminação, existe um sistema burocrático para manter os palestinianos onde estão: sujeitos de formas de colonialismo sustentadas, ainda que mutáveis, ocupação e opressão... é bem provável que exista uma prática de fragmentação, isolamento, transferência e apagamento de palestinianos, mas estes têm de ser primeiro contados, documentados, monitorizados e controlados.")
}

49 Rai, A. (2009). Untimely bollywood: Globalization and india's new media assemblage, p. 9. 
explicação na resposta à multiplicidade, seja como procura com vista à sua inclusão no guião principal e exclusão dessa multiplicidade. Estes diferentes modos de sexualidade refletem-se em duas correntes da teoria queer. A primeira possui uma ênfase desconstrutiva e encontra-se focada na construção social da diferença sexual relativamente à qual a linguagem controla o domínio político através de uma insistência no interminável adiamento de significado..$^{50} \mathrm{O}$ outro modo de compreender a sexualidade pode ser genericamente definido como a multiplicação e proliferação da diferença, de fazer a diferença e de fazer proliferar a diferenciação criativa: tornar-se o oposto da diferença. Neste caso, o "local" da própria linguagem é resignificado; a linguagem não só possui matéria, como é matéria..$^{51}$ As desconstruções da sexualidade deslocam-se para pensar contra e através de binários na esperança de os minar e dissolver, enquanto os segundos, processos afirmativos, têm como proposta ler e incentivar a multiplicidade e a diferenciação interminável na esperança de esmagar esses binários. As capacidades temporais de duração de cada uma das estratégias são diferentes e dispersas nas diferentes escalas. A primeira pode concentrar-se em fazer sentido ou obter um sentido diferente de um formato ou fórum representacional; a segunda pede sentido, a criação de potencialidades de emergência, pelo menos um reinvestimento da forma. Ao invés, encontra-se mais afinada com a diferenciação perpétua de variação para variação e com a multiplicidade de processos afirmativos. ${ }^{2}$

Levando mais longe esta segunda corrente da sexualidade como mosaico e não como identidade, uma corrente investida no pensamento sobre mosaicos e replicação viral, mais do que futurismo reprodutivo, esta corrente poderá realçar a importância do afastamento da retransmissão de chamada e resposta referido acima, que continua a dominar a lógica de argumentação "queer dominante/global" vs. "queer de cor/queer não ocidental", uma retransmissão que não consegue, muitas vezes, interrogar o complexo campo social no qual é produzido o "queer" como significante privilegiado dentro destas fronteiras.

Um dos motivos desta importância poderá, na realidade, residir nas viagens "virais" do conceito de homonacionalismo, tal como foi adotado na América do Norte, em vários países europeus, na Palestina/Israel e na Índia. Nesta aplicação reprodutiva, o homonacionalismo reduziu-se, muitas vezes, a uma plataforma de organização ativista acusatória e como uma análise aplicada à avaliação do nível ou da qualidade do Estado "homonacionalista", que então reifica o Estado como agente dominante, e muitas vezes o único. Recapitulando, em vez de teorizar o homonacionalismo como um posicionamento da identidade ou como uma adjetivação denunciadora de um Estado ou de outra entidade, tenho pensado sobre homonacionalismo como uma análise para apreender a formação do Estado como uma estrutura da modernidade. Tendo em conta

\footnotetext{
${ }^{50}$ Ver Giffney, N. \& Myra. J. (Eds.) (2008). Queering the non/human, pp. 1-12 (para uma explicação destas duas correntes). 51 Ver Kirby, V. (2011). Quantum anthropologies: life at large; Chen, M. (2012). Animacies: biopolitics, racial mattering, and queer affect.

${ }_{52}$ Ver e.g., claire colebrooK (2010). Deleuze and the meaning of life (o trabalho dela é representativo desta segunda abordagem)
} 
este pensamento do homonacionalismo como mosaico, aquilo que significa o homonacionalismo como conceito para ser viral, na verdade, é distinto da sua aplicação reprodutora. Seguindo, então, esta segunda corrente da teoria queer, podemos interessar-nos pelo modo como o homonacionalismo como conceito já está integrado e faz parte do mosaico que é o homonacionalismo, na medida em que as "viagens" discursivas do conceito se replicam viralmente e, assim, operam a mutação do mosaico.

O homonacionalismo como viral e do modo como é adotado pela sociedade de controlo já não é um espelho de si mesmo, já não é um conceito holístico que se reproduz apenas a si mesmo. A maior parte das vezes, a viralidade é invocada na linguagem contemporânea para enunciar o alcance e a velocidade intensificada da circulação de informações, sobretudo em relação à Internet. Também se refere a trocas indiscriminadas, muitas vezes associadas a noções de contaminação corporal, incontrolabilidade, transgressão indesejada da fronteira e dos limites, indicando simultaneamente de modo mais positivo a porosidade, na verdade a convivência, daquilo que tem sido tratado como oposto. 53

Para terminar, então, como poderíamos pensar de modo diferente acerca da viralidade do homonacionalismo, tendo em conta a sua intransigência face à modernidade? O que é que significa dizer que o homonacionalismo se tornou verdadeiramente viral - uma viralidade de mutação e replicação, em vez da banal reprodução do seu quadro de análise nos diferentes contextos nacionais, como aconteceu com algumas das suas utilizações identitárias? O melhor da viralidade, obviamente, é que produz a sua própria crítica, transformando o circuito de chamada e resposta do incitamento ao discurso, de Foucault. Mas, ao contrário deste circuito, que consiste sempre em fazer a acusação de que adotamos a posição do lado de fora, a crítica de uma forma viral já se encontra envolvida desde o seu estado incipiente. Torna-se mais difícil atribuir as culpas ao produto ofensivo supostamente original, uma vez que suscitou a sua própria crítica, e é, assim, alterado através desse encontro.

A reprodução viral não diz respeito ao excesso nem aos complementos; antes, é uma capacidade pós-humana; aquilo que é reproduzido não é o sujeito humano, a identidade ou o corpo, mas tendências afetivas, ecologias de sensações, e diferentes ontologias que criam novas epistemologias de afetos. Quando dizemos que algo se tornou viral, é outra forma de reconhecer que tudo aquilo que é oposto ao vírus, ou o viral, pode ser contornado. A teoria viral, então, como intervenção pós-humanista, também começa antes da separação, como acontece com as espécies, do binário ativismo versus teoria, uma oposição que alicerça a produção nos campos dos estudos Feministas e dos estudos Gays e Lésbicos. A teoria viral é imune a essas separações e divisões. A viralidade indica, não tanto a portabilidade de um conceito, mas uma medida da sua repercussão. Assim, a viralidade também pode constituir uma forma de pensar de modo diferente a transversalidade geopolítica que não é insistentemente encaminhada através ou contra o Estado-nação, proporcionando uma alternativa às noções de transnacionalismo, e complicando a aplicação do conceito de homonacionalismo nos contextos nacionais. É

\footnotetext{
53 Para mais discussões sobre o viral, ver Clough, P. \& Puar, J. (2012). Introduction. Women's studies, 40 (1\&2), Q. 9-.
} 
claro que o homonacionalismo como mosaico constitui uma alternativa à dialética reativa casa-diáspora que informa o projeto do filme I Am ou a interminável transmissão de chamada e resposta do paradigma "o ocidente e o resto".

\section{REFERÊNCIAS}

Ahmed, S. (2011). Problematic proximities: or why critiques of gay imperialism matter. Feminist Legal Studies, 19 (2), 119-32.

Alexander, M. (1994). Not just (any) body can be a citizen: the politics of law, sexuality and postcoloniality in trinidad and tobago and the bahamas. Feminist Revue, 48, 5-23.

Chatterjee, P. (1990). The nationalist resolution of the women's question. In Kumkum Sangari \& Sudesh Vaid (Eds.), Recasting Women: Essays in Colonial History (pp. 233-253). EUA: Rutgers University Press.

Chen, M. (2012). Animacies: biopolitics, racial mattering, and queer affect. Durham, N.C.: Duke University Press.

Chow, R. (2006). The age of the world target: self-referentiality in war, theory, and comparative work. Durham, N.C.: Duke University Press.

Clough, P. \& Puar, J. (2012). Introduction. Women's Studies, 40 (1), 13-26.

Colebrook, C. (2010). Deleuze and the meaning of life. Londres: Continuum.

Deleuze, G. (1997). Negotiations 1972-1990. Nova Yorque: Columbia University Press.

Duggan, L. (2002). The twilight of equality: neoliberalism, cultural politics, and the attack on democracy. Boston: Beacon Press.

Foucault, M. (1977). Security, territory, population: lectures at the collège de France-1978 (Graham Burchell trans., 2007, Londres: Palgrave Macmillan).

Foucault, M. (1998). The will to knowledge: History of sexuality, vol 1 (Robert Hurley trans.). Nova Yorque: Penguin Books.

Giffney, N. \& Myra. J. (Eds.) (2008). Queering the non/human. Burlington: Ashgate Publishing Company, pp. 1-12.

Gilmore, R. (2007). The golden gulag: prisons, surplus, crisis, and opposition in globalizing California. Berkeley: University of California Press.

Haritaworn, J. et. al. (2008). Gay imperialism: gender and sexuality discourse in the 'War on Terror'. In Adi Kuntsman \& Esperanza Miyake (Eds.), Out Of Place: Interrogating Silences in Queerness/Raciality (pp. 9-33). Yorque: Raw Nerve Books Ltd.

Jakobsen, J. \& Pellegrini, A. (2003). Love the sin: sexual regulation and the limits of religious tolerance. Nova Yorque: New York University Press.

Kirby, V. (2011). Quantum anthropologies: life at large. Durham, NC and Londres: Duke University Press.

Livingston, J. \& Puar, J. (2011). Introduction: interspecies. Social Text 29 (1 106), 3-14.

Long, S. (2009). Unbearable witness: how western activists (mis)recognize sexuality in Iran. Contemporary Politics, 15 (1), 119-36. 
Panagia, D. (2009). The political life of sensation. Durham e Londres: Duke University Press.

Puar, J. (2014, no prelo ). Affective politics: states of debility and capacity.

Puar, J. (2012). I'd rather be a cyborg than a goddess, PhiloSOPHIA, 2 (1), 49-66.

Puar, J. (2012). The cost of getting better: suicide, sensation, switchpoints. GLQ: Journal of Lesbian Q Gay Studies, 18 (1), 149-58.

Puar, J. (2011). Citation and censorship: the politics of talking about the sexual politics of Israel. Feminist Legal Studies, 19 (2), 133-42.

Puar, J. (2005). Terrorist assemblages: homonationalism in queer times. Durham e Londres: Duke University Press.

Puar, J. (1998). Transnational sexualities: south asian (trans)nation(alism)s and queer diasporas. In David L. Eng \& Alice Y. Hom (eds.), QđA: Queer in Asian America. Filadélfia: Temple University Press.

Rai, A. (2009). Untimely bollywood: globalization and india's new media assemblage. Durham e Londres: Duke University Press.

Ratti, R. (Ed.) (1993) A lotus of another color: an unfolding of the south asian gay and lesbian experience. Boston: Alyson.

Reddy, C. (2011). Freedom with violence: race, sexuality and the US state. Durham e Londres: Duke University Press.

Schulman, S. (2012). Israel/ Palestine and the queer international. Durham, NC: Duke University Press.

Shah, N. (1998). Sexuality, identity, and history. In David L. Eng \& Alice Y. Hom (Eds.), QQA: Queer in Asian America. Filadélfia: Temple University Press.

Sircar, O. (2012). Spectacles of emancipation: reading rights differently in India's legal discourse. Osgoode Hall Law Journal, 49 (3), 527-573.

Solomon, A. (2003). Viva la diva citizenship: post-zionism and gay rights. In Daniel Boyarin et. al. (Eds.). Queer Theory and the Jewish Question (pp. 149-65). Nova Yorque: Columbia University Press.

Spivak, G.C. (1988). Can the subaltern speak?. In Lawrence Gossberg \& Cary Nelson (Eds.), Marxism and the Interpretation of Culture (pp. 271-313). Urbana: University of Illinois Press.

Stein, R- (2010). Explosive: scenes from Israeli queer occupation. GLQ: Journal Lesbian Q Gay Studies, 16 (4), 517-36.

Tawil-Souri, H. (2011). Colored identity: the politics and materiality of id cards in palestine/ Israel. Social Text, 29 (2 107), 67-97.

Weston, K. (1997). Families we choose: lesbians, gays, kinship. Nova Yorque: Columbia University Press.

Jasbir K. Puar é Associate Professor de Estudos Feministas e de Género na Rutgers University. Doutorou-se em Estudos Étnicos na University of California at Berkeley em 1999, depois de ter concluído o Mestrado em Estudos Feministas na Universidade de York, em Inglaterra, em 1993. Puar é autora de Terrorist Assemblages: Homonationalism in Queer Times (Duke University Press 2007), que conquistou em 2007 o prémio 
literário Cultural Studies Book Award da Association for Asian American Studies. Entre os trabalhos editados por Puar, encontram-se: "Queer Tourism: Geographies of Globalization" (GLQ: A Journal of Lesbian and Gay Studies, 2002); é co-editora de volumes sobre Sexualidade e espaço (Society and Space, 2003); Inter-espécies (Social Text, 2011); Viral (Women's Studies Quarterly, 2012). Os seus artigos foram publicados nas revistas científicas Gender, Place, and Culture, Radical History Review, Socialist Review, Feminist Legal Studies, Antipode: A Radical Journal of Geography, Feminist Studies, e Signs: Journal of Women in Culture and Society.

E-mail: jpuar@rci.rutgers.edu

Rutgers University 190 University Ave, Newark, NJ 07102, EUA 